\title{
Development of a Candy Hybrid Rocket Motor for Undergraduate Space Education
}

\author{
By Yutaka Wada, ${ }^{1)}$ Yo Kawabata, ${ }^{1)}$ Kenji OGimoto, ${ }^{2)}$ Hiroaki AkIYAma, ${ }^{3)}$ Takao Yanagi, ${ }^{4)}$ and Seiichi SaKamoto ${ }^{5)}$ \\ ${ }^{1)}$ Chiba Institute of Technology, Narashino, Japan \\ ${ }^{2)}$ SOUKI Systems Co. Ltd., Osaka, Japan \\ ${ }^{3)}$ Wakayama University, Wakayama, Japan \\ 4)Hakuhodo DY Media Partners Inc., Tokyo, Japan \\ 5) National Astronomical Observatory of Japan (NAOJ), Mitaka, Japan
}

(Received June 23rd, 2017)

\begin{abstract}
In this study, a reusable educational motor that can burn different types of materials in the chamber was developed. Specifically, five candidate sweets were selected as fuel and burnt. The combustion performances of these sweets were compared, and the soft candy was selected as the solid fuel to be used in the motor, because it had the highest total impulse. The SOUKI Systems Co. Ltd. designed a small candy hybrid rocket based on these results. The candy rocket was launched successfully using soft candy at the Kada Cosmo Park. The motor carried the candy rocket to $319 \mathrm{~m}$ altitude and was fully functional under the high-acceleration environment.
\end{abstract}

Key Words: Hybrid Rocket, Fuel, Combustion, Launching Experiment, Space Education, Candy Rocket Project

\section{Introduction}

A hybrid rocket propulsion system is known for its nonexplosive propulsion that is achieved because the inert polymer acting as the solid fuel and the liquid oxidizer are separately stored. A massive hybrid rocket system has never been implemented owing to the low thrust, primarily resulting from the low fuel regression rate. Therefore, some high-regression rate fuels and effective combustion techniques are being proposed by several researchers. ${ }^{1-8)}$ However, hybrid rockets have numerous advantages: throttlability, environmentally friendly nature, simplicity, and low cost. Based on these characteristics, hybrid rockets are expected to be excellent educational tools for undergraduate students. A small hybrid rocket has already developed under the rocket launch program of the undergraduate space education at several university in Japan, and the program have been launching the rocket using the HyperTEK ${ }^{9}$ system, manufactured by Cesaroni Technology Inc. in Canada, every August during the Noshiro Space Event held in the Akita prefecture and every March during the Oshima Space Event organized in Tokyo. The HyperTEK system is highly safe and useful as a large thrust generation system in comparison with other educational rocket motors. It utilizes Acrylonitrile-styrene-acrylate (ABS) resin as the solid fuel and liquid $\mathrm{N}_{2} \mathrm{O}$ as the oxidizer. The fuel grain is a disposable system. For performing numerous experiments, it is necessary to prepare the fuel grains for each experiment. However, this system is not suitable for learning rocket propulsion engineering because students can only be users of this engine.

One of the benefits of a hybrid rocket is that a wide range of high-calorie solid materials can be selected as the fuel. Therefore, in this study, we developed a new hybrid rocket motor that can be used with several solid materials as the hybrid rocket fuel, and applied it as a motor for the education of high school and undergraduate students. The detailed results of the development of the educational motor, combustion tests, and launch experiment are reported in this paper.

\section{Motor Development}

\subsection{Rocket motor case}

Figure 1 shows a schematic of HyperTEK fuel grain and our proposed hybrid rocket motor. Table 1 compares our educational motor and the HyperTEK fuel grain. The HyperTEK fuel grain motor is made of ABS resin. Though the HyperTEK motor has been designed as a highly simple, lightweight system, it cannot be reused because its inside wall is burned directly as fuel by the oxidizer. In this study, we selected liquid $\mathrm{N}_{2} \mathrm{O}$ as the oxidizer on account of its high vapor pressure at room temperature, which is useful for pressurizing gas.

The educational motor has a length of $339 \mathrm{~mm}$, an outer diameter of $82 \mathrm{~mm}$, and an inner diameter of $50 \mathrm{~mm}$. The motor has a burning region, which has a larger volume than the HyperTEK system, for burning different types of fuels. The motor case is made of aluminum, and it can be reused. The baffle plate, made of polymethyl methacrylate (PMMA), is set inside the chamber to trap and hold the fuel grain at the front of the burning region and for increasing combustion efficiency. The ignition fuel is in the outer periphery of the combustion chamber, and a spark wire is used for ignition. A low melting temperature point fuel (LT fuel) was chosen as the ignition fuel 
to have a high regression rate and excellent ignition.

The experimental conditions of our motor are listed in Table 2.

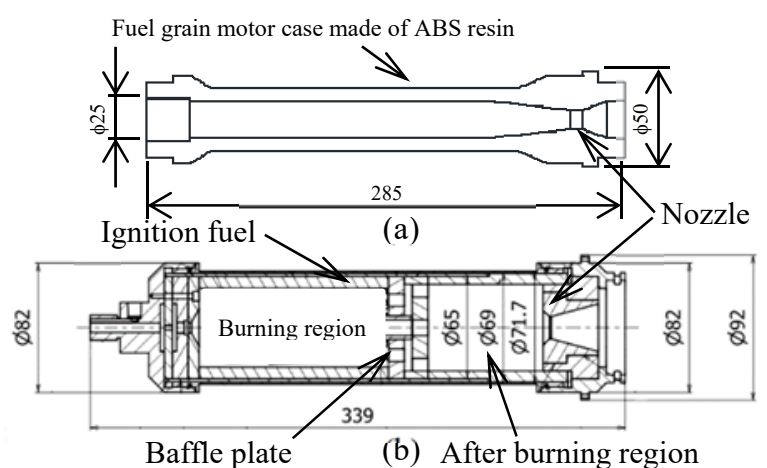

Fig. 1. (a) HyperTEK fuel grain motor, (b) schematic view of our hybrid rocket motor.

Table 1. Comparison of our hybrid rocket motor and the HyperTEK fuel grain motor.

\begin{tabular}{lrr}
\hline Unit: $\mathrm{mm}$ & Original motor case & HyperTEK fuel grain \\
\hline Length & 339 & 285 \\
Outer diameter & 82 & 50 \\
Inner diameter & 50 & 25 \\
\hline
\end{tabular}

Table 2. Experimental conditions of our hybrid rocket motor.

\begin{tabular}{lr}
\hline Burn time (s) & 3 \\
Combustion pressure $(\mathrm{MPa})$ & 2.5 \\
Oxidizer mass flux $\left(\mathrm{kg} / \mathrm{m}^{2} \cdot \mathrm{s}\right)$ & 70 \\
Measurement items & Oxidizer pressure \\
& Combustion pressure \\
& Thrust \\
& Video recoding \\
\hline
\end{tabular}

\subsection{Fuel}

In hybrid rockets, resin, rubber, or wax is typically used as solid fuel. Additionally, this educational motor is able to use several hydrocarbon-based materials as fuel in the burning region. In this study, various sweets rich in sucrose were selected as fuels. Figure 2 shows the theoretical performance of specific impulse (Isp) at sea level with sucrose and $\mathrm{N}_{2} \mathrm{O}$ under the NASA chemical equilibrium with applications (CEA) program. The fuel performance of Hydroxyl-terminated polybutadiene (HTPB), a solid rocket propellant, is also shown for comparison in Fig. 2. Sucrose, which has the chemical formula $\mathrm{C}_{12} \mathrm{H}_{22} \mathrm{O}_{11}$, has a higher oxygen content than HTPB. Therefore, the performance of sucrose is lower than of HTPB. To obtain high rocket performance by using sucrose fuel, a large amount of fuel gas is necessary.

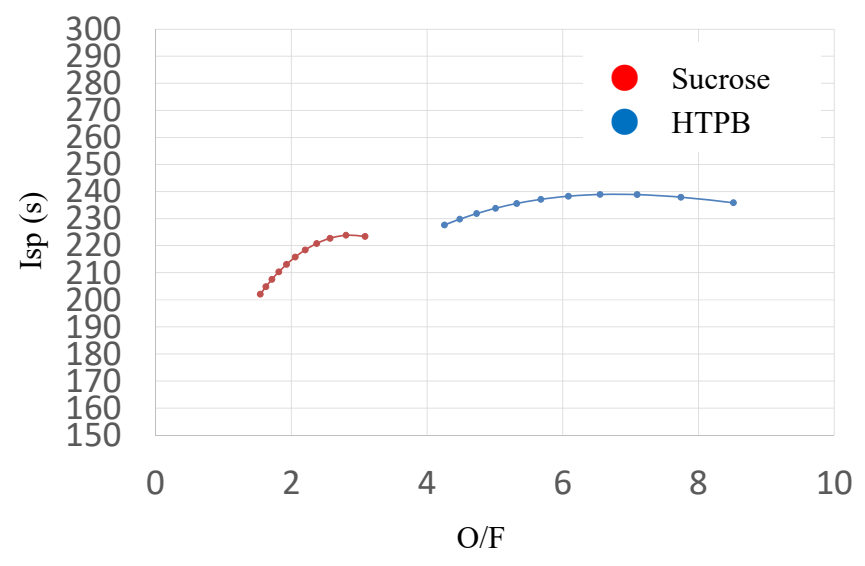

Fig. 2. Comparison of the Isp (sea level) performances for sucrose and HTPB (Combustion pressure: $3 \mathrm{MPa}$ ) as fuels.

The sucrose based sweets used as the fuel in this study are listed in Table 3. It can be seen that sweets from several foreign countries are selected. The mass of each type of fuel in the combustion chamber was $64 \mathrm{~g}$; only the mass of the fortune cookie was lower, i.e., $28 \mathrm{~g}$ owing to its low density. Figures 3 and 4 show the photographs of each sweet.

\begin{tabular}{ll}
\multicolumn{1}{c}{ Table 3. } & \multicolumn{1}{c}{ Sweets chosen as candidate fuels. } \\
\hline \multicolumn{1}{c}{ Candidate sweets } & Shape \\
\hline Soft Candy Puccho (Japan) & Block candy \\
Snickers (U.S.A.) & Stick \\
HARIBO (Germany) & Small gummi \\
Madeleine (France) & Soft cookie \\
Fortune cookie (China) & Hard cookie
\end{tabular}

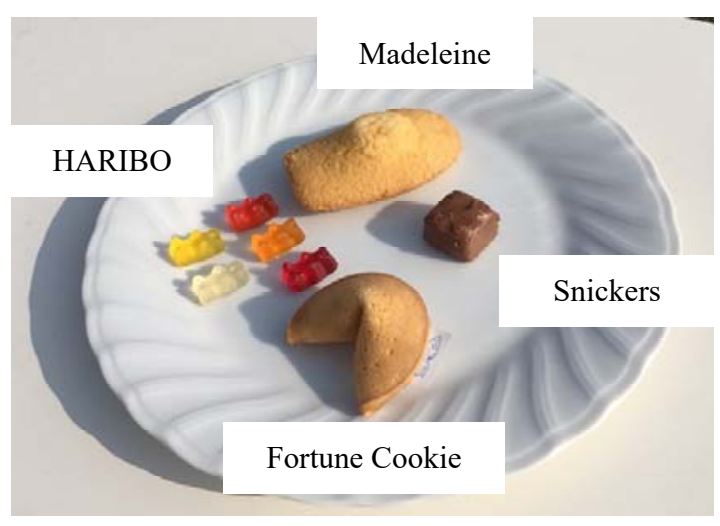

Fig. 3. Sweets as candidate hybrid rocket fuels. 


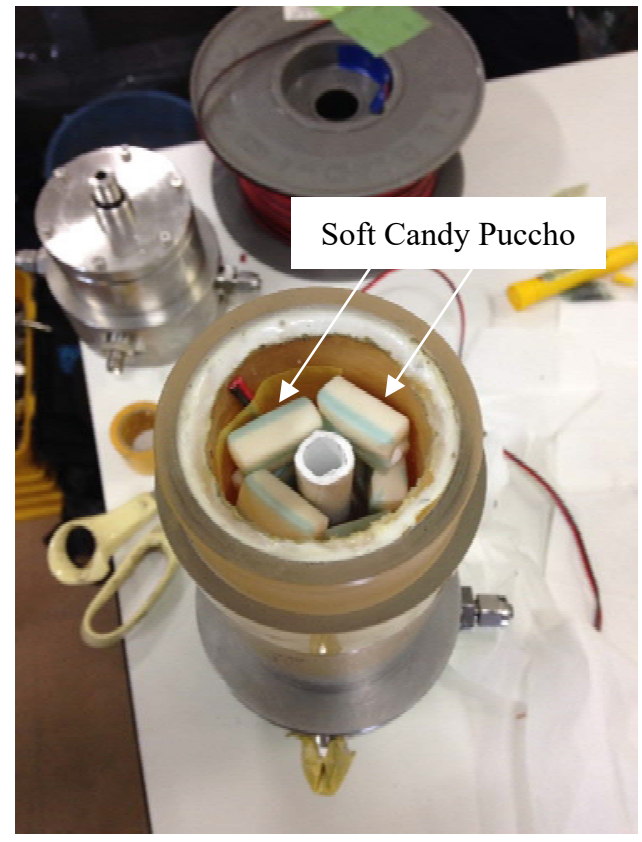

Fig. 4. Soft candy Puccho in the chamber.

\subsection{Firing test}

All the firing tests were successful, and we could obtain the pressure and thrust profiles during combustion; however, we lost the Madeleine test data because of human error. Figure 5 and Table 4 show obtained data of the thrust curve and test results for each sweet. Snickers has the largest thrust of approximately $600 \mathrm{~N}$, and its average thrust is also a large value of approximately $418.3 \mathrm{~N}$. However, an extremely short burn time $(1.76 \mathrm{~s})$ is measured for it, which might be because of the meltable material (chocolate), which is the main component of Snickers. HARIBO exhibits a poor performance compared with other sweets. After the HARIBO test, we found some unburnt HARIBOs on the ground in the exhaust direction. This suggests that some of the small HARIBOs were ejected outside through the baffle plate and nozzle when it was ignited. The combustion oscillation is observed at a short burning time for the fortune cookie. A fortune cookie is very hard and brittle; therefore, it is theorized that the cookies are broken by the impact of the ignition and passed through the nozzle causing combustion oscillation. The firing test of the soft candy produces a very stable thrust curve and the highest total impulse (921.7 Ns) is recorded for it. The reason for the stable combustion is that the soft candy is harder and has better elasticity as a solid fuel, and it burns uniformly on the solid surface. Its average thrust level is $351.8 \mathrm{~N}$, average oxidizer mass flux range is $300 \mathrm{~kg} / \mathrm{m}^{2} \mathrm{~s}$, average pressure range $2.5 \mathrm{MPa}$, and burning time $2.62 \mathrm{~s}$. Therefore, in this propulsion system, the Japanese soft candy was chosen as the hybrid rocket fuel. However, students can select other fuels on the basis of the rocket propulsion engineering design.

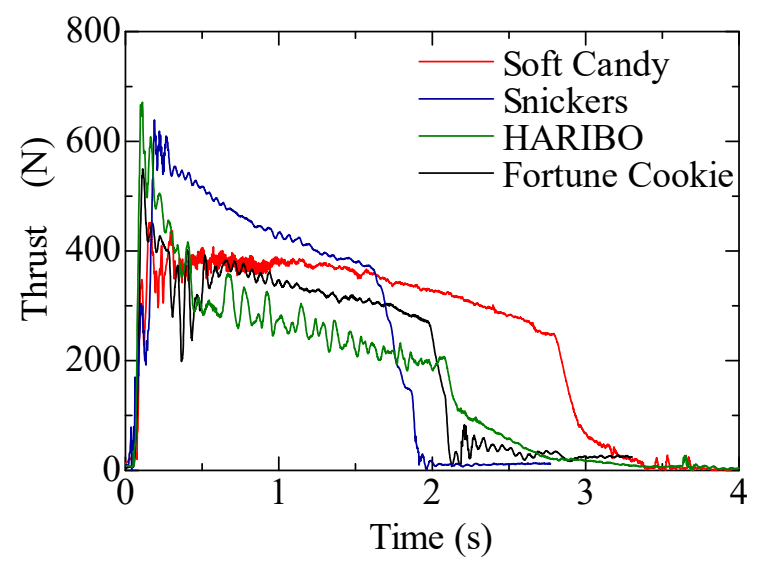

Fig. 5. Comparison of the combustion results of the sweets.

Table 4. Results of the firing tests.

\begin{tabular}{lcrl}
\hline Sweets & $\begin{array}{l}\text { Ave. thrust } \\
\text { / Burn Time }\end{array}$ & Isp & Result \\
\hline Soft candy & $351.8 \mathrm{~N} / 2.6 \mathrm{~s}$ & $168.2 \mathrm{~s}$ & $\begin{array}{l}\text { Highest total } \\
\text { impulse }\end{array}$ \\
Snickers & $418.3 \mathrm{~N} / 1.8 \mathrm{~s}$ & $162.3 \mathrm{~s}$ & $\begin{array}{l}\text { Highest thrust } \\
\text { HARIBO }\end{array}$ \\
$\begin{array}{l}\text { Madeleine } \\
\begin{array}{l}\text { Fortune } \\
\text { cookie }\end{array}\end{array}$ & Not measured & Not measured & $\begin{array}{l}\text { - } \\
\text { completely }\end{array}$ \\
\hline
\end{tabular}

\section{Small Rocket Launch Experiment}

We designed a small rocket based on these results and conducted a launch experiment in Japan. Four hybrid rockets equipped with the candy motor were launched successfully. Two of them were for the Candy Hybrid Rocket project, other two were for an educational program.

\subsection{Candy hybrid rocket project}

Here, we introduce the Candy Rocket Project under which the first launching experiment was conducted using the educational motor.

A launch experiment of a candy rocket was tested at the Kada Cosmo Park in Wakayama Prefecture on Saturday, March 7, 2015. The rocket was developed by SOUKI Systems Co. Ltd. The launching experiment was attempted twice and was successful. Specifications of the rocket are shown in Fig. 6 and Table 5.

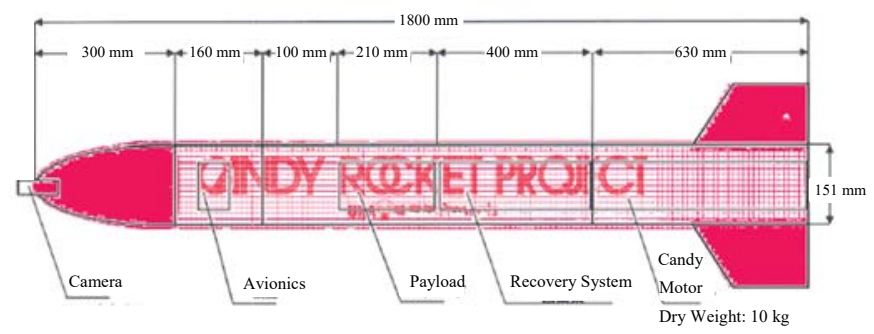

Fig. 6. Schematic of the candy motor-loaded hybrid rocket. 


\begin{tabular}{cc} 
Table 5. Specifications of the candy motor-loaded rocket. \\
\hline Length & $1800 \mathrm{~mm}$ \\
Diameter & $150 \mathrm{~mm}$ \\
Dry weight & $10 \mathrm{~kg}$ \\
Motor & Candy hybrid rocket \\
Recovery & Parachute \\
Cal. altitude & Approximately $313 \mathrm{~m}$ \\
Drop speed & Approximately $9 \mathrm{~m} / \mathrm{s}$ \\
Down range & $100 \mathrm{~m}$ around \\
Payload & Video camera \\
& Acceleration sensor \\
& Pressure sensor \\
& Sound beacon for recovery \\
\hline
\end{tabular}

The experiment was conducted twice using similarly shaped rockets. The loaded sensors were also successful in measuring the acceleration and atmospheric pressure. Figure 7 shows the analysis results of the measured pressure sensor data. According to it, the rocket practically attains the predicted altitude and drop speed. The motor carries the candy rocket to $319 \mathrm{~m}$ in altitude and is fully functional under the highacceleration environment, as shown in Fig. 8.

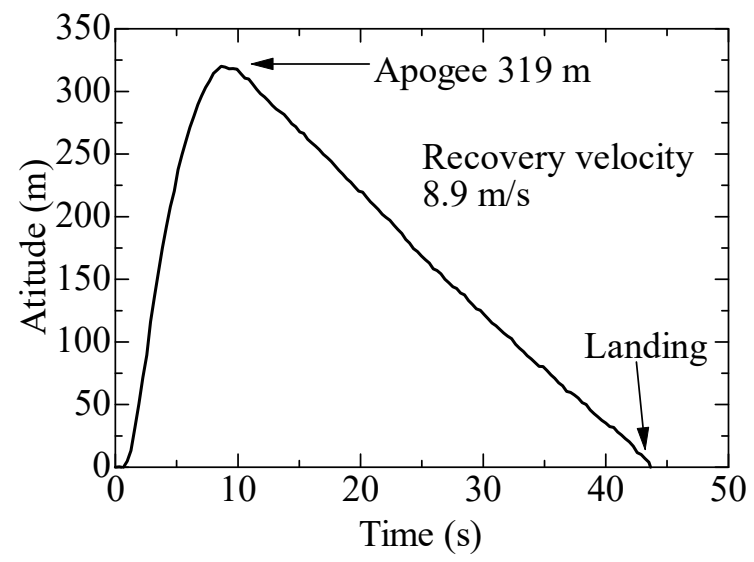

Fig. 7. Analysis data from the pressure sensor.

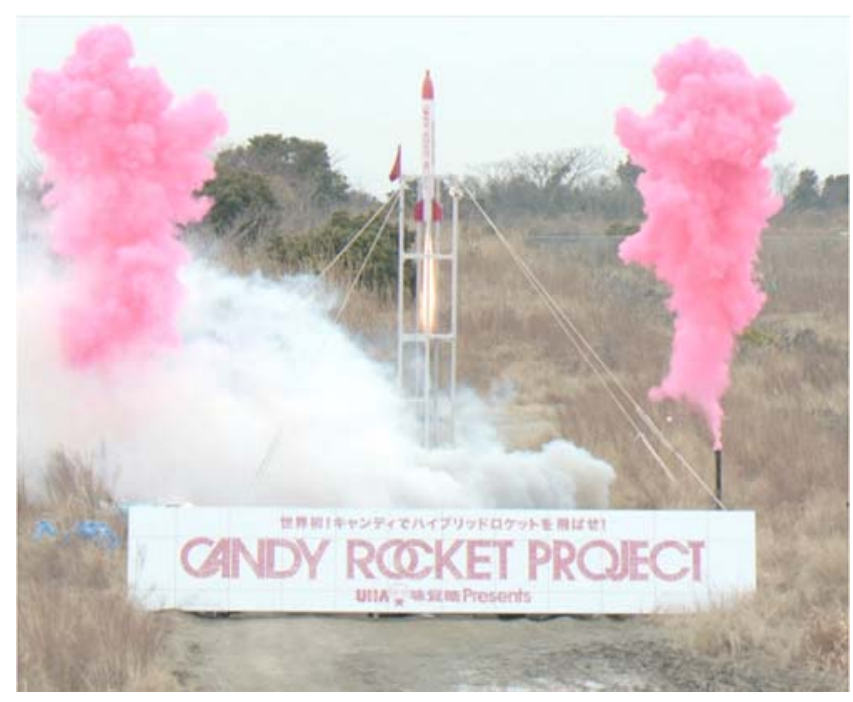

Fig. 8. Successful launch of the candy rocket.
When launching the candy rocket, we invited approximately 20 children and assembled the candy rocket engine in front of them. Most of the children could not imagine that a rocket could be launched using soft candy as a fuel. We jubilated at the time of the rocket launch having satisfied the expectations of the children. The launch was a tremendous success for the field of space education.

In addition, this candy rocket was the first global challenge of its type, and was covered by various forms of the media. On the television, it was featured in 17 programs with detailed commentary. It was reported in 23 newspapers, and it is noteworthy that it was also published in sports newspapers that are not even remotely connected with space development. It was also highlighted on 550 news web sites. ${ }^{10)}$ Numerous English translations were also provided to the foreign media and reported in more than 30 countries worldwide. From these facts, we believe that sufficient results supporting space education have been provided indirectly through the media.

\subsection{Educational program for rocket girls and boys ${ }^{11)}$}

The educational program for rocket girls and boys pertains to the design, construction, and launching of the small hybrid rocket by a group of high school students of approximately 20 members, and it is conducted every year. Several high school students join this program, and not only design and develop rockets, but also learn project management. In 2016, two rockets, labelled separately as team A and team B, were developed, and launched using the candy rocket motor for learning propulsion engineering. Figures 9 and 10 illustrate the schematic of the two rockets, and Tables 6 and 7 list their specifications.

\section{$360^{\circ}$}

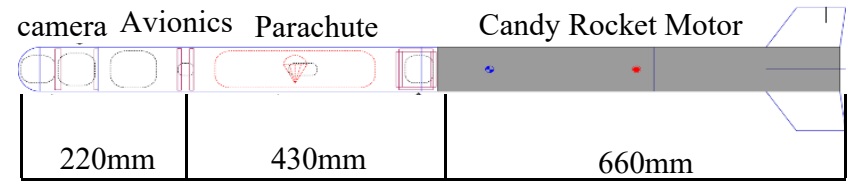

Fig. 9. Schematic of the candy motor-loaded hybrid rocket of team A.

\begin{tabular}{cr} 
Table 6. Specifications of the rocket of team A. \\
\cline { 1 - 2 } Rocket name & MP3 \\
Length [mm] & 1310 \\
Diameter [mm] & 89 \\
Wet weight [g] & 4240 \\
Dry weight [g] & 3670 \\
Cal. altitude [m] & 1289 \\
Motor & Candy rocket motor \\
\hline
\end{tabular}

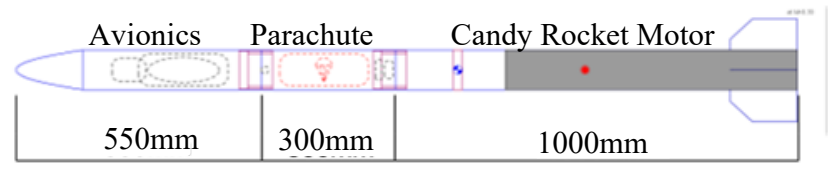

Fig. 10. Schematic of the candy motor-loaded hybrid rocket of team B. 
Table 7. Specifications of the rocket of team B.

\begin{tabular}{cr}
\hline Rocket name & Flying chicken \\
Length [mm] & 1750 \\
Diameter [mm] & 89 \\
Wet weight [g] & 4652 \\
Dry weight [g] & 4322 \\
Cal. altitude [m] & 1187 \\
Motor & Candy rocket motor \\
\hline
\end{tabular}

These rockets were launched at the Izu Oshima Island in the Tokyo metropolitan from March 25 to 27, 2017. The ignition of both the rockets was successful; however, the parachute of team A's rocket got detached because of the huge opening shock of the parachute, and the rocket had a hard landing. The recovery system of the rocket of team B did not work and it also had a hard free fall landing. Figures 11-13 show the photographs of these rocket launches and the recovered rocket of team B.

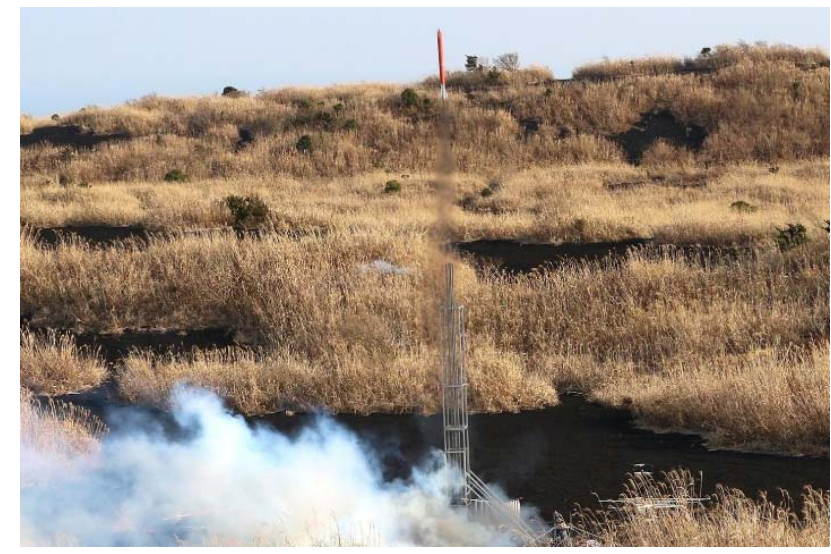

Fig. 11. Rocket launch of team A.

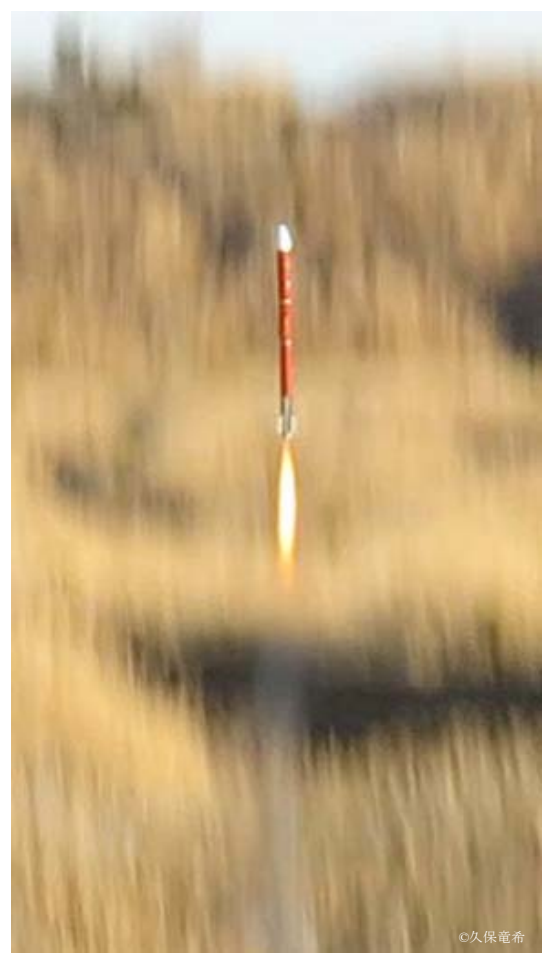

Fig. 12. Rocket launch of team B.

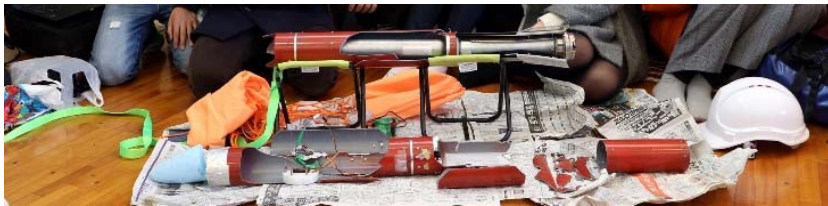

Fig. 13. Broken rocket from the hard landing of team B.

\section{Conclusions}

In this study, a reusable educational hybrid rocket motor was developed and was successfully launched four times. This motor could burn various materials as fuels. Therefore, high school students and undergraduate students can use it to learn rocket propulsion engineering. Members of the educational program for rocket girls and boys, who were high school students, used the educational motor to launch experiments and succeeded in their educational program.

Through this study, we want people to learn that creative thinking could turn an everyday material, such as candy, into something entirely different like rocket fuel. We want to communicate the importance of imagination, fascination of science, and the joy of creative manufacturing to people in every strata of society.

\section{References}

1) Yuasa, S., Yamamoto, K., Hachiya, H., and Kitagawa, K.: Development of a Small Sounding Hybrid Rocket with a SwirlingOxidizer-Type Engine, AIAA Paper 2001-3537, 2001.

2) Nagata, H., Ito, M., Maeda, T., Watanabe, M., Uematsu, T., Totani, T., and Kudo, I.: Development of CAMUI Hybrid Rocket to Create a Market for Small Rocket Experiments, Acta Astronaut., 59 (2006), pp. 253-258.

3) Karabeyoglu, M. A., Cantwell, B. J., and Altman, D.: Development and Testing of Paraffin-based Hybrid Rocket Fuels, AIAA Paper 2001-4503, 2001

4) Wada, Y., Jikei, M., Kato, R., Kato, N., and Hori, K.: Application of Low Melting Point Thermoplastics to Hybrid Rocket Fuel. Trans. JSASS, Aerospace Tech.Japan, 10, ists28 (2012), pp. Pa_1-Pa_5.

5) Kawabata, Y., Wada, Y., Kato, N., Hori, K., and Nagase, R.: Study on Improvement of Mechanical Characteristics of LT Fuels for Hybrid Rocket, Thirteenth International Conference on Flow Dynamics, Sendai, Japan, OS8-22, 2016.

6) Wada, Y., Kato, R., Kato, N., and Hori, K.: Small Rocket Launch Experiment using Low Melting Point Thermoplastic Fuel/ $\mathrm{N}_{2} \mathrm{O}$ Hybrid Rocket, AIAA Paper 2013-4050, 2013.

7) Wada, Y., Kawabata, Y., Shinnakazaki, K., Kato, R., Kato, N., and Hori, K.: A Study on Combustion Efficiency Improvement of Low Melting Temperature Thermoplastics as a Hybrid Rocket Fuel, Trans. JSASS, Aerospace Tech. Japan, 12, ists29 (2014), pp. Pa_9$\mathrm{Pa} \_14$.

8) Ozawa, K., Kitagawa, K., and Shimada, T.: Performance Calculations and Burning Tests on Altering-intensity Swirling Oxidizer Flow Type Hybrid Rocket Engines, $66^{\text {th }}$ International Astronautical Congress, Jerusalem, Israel, IAC-15.C4.2.5, 2015.

9) HyperTEK web site, http://www.hypertekhybrids.com (accessed April 17, 2017).

10) Candy Rocket Project in UHA-mikakuto web site, https://www.uhamikakuto.co.jp/candyrocket/en/ (accessed April 17, 2017).

11) Educational Program for Rocket Girls and Boys web site, http://www.it-chiba.ac.jp/rocket/rokega.html (in Japanese) (accessed April 17, 2017). 